\title{
SOBRE A PRESENÇA DE SÓCRATES NA PSICANÁLISE ${ }^{1}$
}

\author{
Anna Carolina Lo Bianco ${ }^{2}$ \\ Universidade Federal do Rio de Janeiro
}

RESUMO: Não tendo deixado uma obra escrita, podemos dizer que o pensamento de Sócrates que chega até nós é fundado sobre um ponto básico, central e caro também à experiência psicanalítica: o da presença diante do outro. $O$ artigo examina as características que cercam o exercício do procedimento socrático, ressaltando o impacto que ele tem sobre o interlocutor. Procura, em seguida, tomar a sua riqueza de princípios para ver, com as lentes da própria psicanálise, em que estes oferecem algumas condições de possibilidade para o melhor desenvolvimento de suas formulações.

Palavras-chave: presença de Sócrates; presença do psicanalista

\section{ON THE PRESENCE OF SOCRATES IN PSYCHOANALYSIS}

ABSTRACT: Since Socrates never wrote a work, we can assume that the thought we received from him is based in one point that is central and very dear to Psychoanalysis as much as it is to this same thought: the presence in face of the other. The article examines the characteristics of Socratic procedures highlighting the impact it has on its interlocutor. Then, it takes the wealthy of principles of Socrates to examine, using the lenses of psychoanalysis itself, the conditions these principles offer to better develop Psychoanalytic formulations.

Key words: Presence of Socrates; presence of Psychoanalysis.

"(La sua) missione era la sua personalità in atto, atraverso i suoi rapporti concreti" (Banfi, 1944 conforme citado por Magalhães-Vilhena, 1984)

Não tendo deixado uma obra escrita, podemos dizer que o pensamento de Sócrates que chega até nós é fundado sobre um ponto básico, central e caro também à experiência psicanalítica: o da presença diante do outro. Esta presença, responsável pela marca e pelo impacto característicos que o procedimento socrático exerce sobre seu interlocutor é, ao mesmo tempo, o signo distintivo da psicanálise em relação a qualquer outro sistema doutrinário ou filosófico. E, se Freud deixou uma obra em que os conceitos psicanalíticos se desenvolvem com precisão e rigor e representações analíticas corretas são feitas

\footnotetext{
1 Artigo recebido para publicação em 06/2001; aceito em 10/2001

2 Endereço para correspondência: Anna Carolina Lo Bianco, Programa de Pós-Graduação em Teoria Psicanalítica, Instituto de Psicologia, UFRJ, Campus da Praia Vermelha, Av. Pasteur, 250, fundos, Rio de Janeiro, RJ, CEP 22290-240. E-mail aclobianco@gbl.com.br
}

acerca das observações do cotidiano é porque a dimensão escrita é acrescentada àquela em que na verdade a experiência psicanalítica opera: a da presença do analista frente ao analisando.

Nosso objetivo, no presente trabalho, é tentar, com um cuidado proporcional à amplitude do tema, examinar os caminhos que são possibilitados, abertos e transpostos por uma tal postura frente àqueles com os quais se diz que Sócrates encontrou. Este exame nos levará a apontar nele este caráter que Lacan (1966) pôs em relevo e que o coloca no lugar de "precursor do analista"

Tratá-lo como precursor, no entanto, é paradoxalmente atribuir e ressaltar em Sócrates $a$ posteriori qualidades ou procedimentos que foram valorizados ou iluminados, se podemos dizer, pelo ponto de vista do analista. Ou seja, Sócrates não é

\footnotetext{
'Muitos autores ressaltam que Sócrates foi considerado precursor de quase tudo. Acreditamos que aí esteja um ponto básico do personagem, cuja própria vida e ensinamento, por não oferecerem uma solução final para o saber, estão sempre podendo ser reivindicadas e continuadas por novas proposições.
} 
analista. O pensamento de Sócrates não é o pensamento psicanalítico. Não nos oferecem, portanto, a possibilidade de uma analogia ponto a ponto. Tratase de apenas tomar a sua riqueza de princípios para ver, com as lentes da própria psicanálise, em que estes oferecem algumas condições de possibilidade para o melhor desenvolvimento de seus processos, conceitos, formulações e experiências.

Não procuraremos, portanto, entrar na seara dos estudos sobre Sócrates. No entanto, sabemos que seara e personagem, na sua complexidade, sobre os quais praticamente tudo que se disse também se negou ou se contrariou (ver, por exemplo, MagalhãesVilhena, 1984), evidenciam um enigma cuja função principal parece ser exatamente motivar exercícios que, ainda que tendam assintomaticamente para sua solução, mobilizem e façam girar idéias, questionamentos e atos.

A própria característica da figura de Sócrates que nos importa enfatizar

"a escolha pela comunicação direta e viva do diálogo oral" (Pessanha,1996, p.13)

Nos apresenta um problema que os estudiosos apontam como de quase impossível definição. Não havendo deixado uma obra escrita, é preciso que se recorra ao que sobre ele se escreveu. Seus contemporâneos Platão, Xenofonte e Aristófanes são os que nos fornecem as versões sobre Sócrates. Algumas críticas foram feitas aos dois últimos (Pessanha,1996). Não nos sendo possível nem necessário entrar nesta controvérsia, procuraremos lançar mão, então, do testemunho de Platão.

Tentaremos, pois, recorrer à figura de Sócrates, tal como nos foi dada pelo Platão, principalmente em seus diálogos iniciais. Nela iremos fazer um recorte conceitual balizado por três pontos: sua agrafia, o impacto de sua presença e a efetividade de seu procedimento. A nosso ver estes estão imbricados e possibilitam a delimitação do contorno de uma questão, como dissemos, cara à psicanálise: a da interrogação que é feita na presença do interlocutor, implicando-o no ato mesmo desta interlocução.

\section{A agrafia de Sócrates}

As fontes iniciais sobre Sócrates são quase unânimes em afirmar que ele não deixou qualquer obra escrita. Levanta-se, é verdade, uma ligeira controvérsia sobre este assunto, como de resto sobre tudo que cerca sua vida. Mas, mesmo com o aparecimento de textos apócrifos que lhe são atribuídos e com a crítica de que a própria convicção que cerca seu "silêncio literário" é mais uma das lendas que correm sobre ele, há poucas razões para se acreditar que ele haja realmente escrito (Magalhães-Vilhena, 1984). Apesar de ser uma época em que as obras em prosa não são habitualmente escritas, já havia um certo número de autores que deixavam sua produção literária registrada como, por exemplo, Ésquilo, Sófocles, Píndaro, Eurípides e Aristófanes (Brun,1992). Alguns autores se perguntam se esse é apenas um "detalhe interessante e original" ou um "acidente lamentável" e irrecuperável (Lasa, 1991, p.25).

No momento, é importante que, para além do exame das razões da agrafia de Sócrates, possamos valorizá-la na sua positividade, nos efeitos que engendra, nas situações que possibilita, nas redes que afeta, ou seja, na superfície que cria, exatamente por esta ausência de escrita. Efeitos que impossibilitavam que dele comentaristas e críticos vivessem fazendo a exegese que alimentaria seu próprio ensinamento petrificado, para glorificá-lo. Situações que incentivavam o contacto insubstituível com os que lhe escutavam, rodeavam e pelos quais se interessava, afetando desta forma a rede das relações empedernidas entre mestre e discípulos em que o saber veiculado corria sempre de um para outros. Finalmente, superfície que proporcionava o exercício do que mais caracterizava Sócrates e sua atividade: a conversa (Pessanha, 1996).

Procurando considerar como matéria-prima as propriedades mesmas de sua aversão pela escrita, vemos o que acarretam e o que comportam para a reflexão sobre as questões da presença e do método anteriormente mencionadas. Se Sócrates não escreve, sua palavra só pode ser situada, difundida, pesada, aceita ou rejeitada num diálogo em que esteja necessariamente engajado, frente a alguém que o escuta. Se Sócrates não escreve, não recorre à palavra escrita para dar seus ensinamentos, é porque espera, valoriza e provoca algum impacto sobre o interlocutor. Logo, se impõe a importância e a força da presença de Sócrates frente àquele com quem se depara. 


\section{A presença de Sócrates}

Nas palavras de Jaeger (1936/1995), Sócrates é "o homem do momento, num sentido absolutamente elementar" (p.512). Momento no que este termo comporta de um recorte circunscrito de uma duração, para tomá-lo em toda a intensidade e, se pudermos falar assim, concretude no instante mesmo em que ocorre. É como se Sócrates não se preocupasse em estabelecer um ensinamento acabado, de forma doutrinária, em oferecer uma mensagem doutrinária, mas em se dirigir a uma "mensagem de vida" que englobasse as dimensões prosaicas do cotidiano (Koyré, 1937). E, neste sentido pode-se ver como a presença frente ao outro implica uma verdade alcançada num âmbito que a palavra escrita não poderia permitir. $O$ contato com um texto é inteiramente limitador e diferente daquele que resulta do confronto com o outro. Jamais se pode esperar interrogar e obter de um texto escrito o que se interroga e se obtém numa relação em que o outro está presente em sua imediação, em sua reação bruta, não medida e não prevista.

Sócrates não procura, naqueles com que se encontra, discípulos que simplesmente registrem a fala do mestre, fala que seguiria sempre o mesmo caminho, deste para aquele, que traria pronto um saber escrito e estabelecido, que seria motivo de apreciação e avaliação constante dos sábios. Sócrates vivia "no e pelo contacto com um discípulo do qual recebia tanto quanto o discípulo poderia receber dele" (Brun, 1992, p.47). Isto incluía também os bens materiais que poderiam ter the sido proporcionados pelo cumprimento do que, a partir de um dado momento de sua vida, passou a ver como sua missão, e pelo qual não costumava receber (Platão, 1956). Esta missão lhe havia sido confiada pelo oráculo de Delfos, que o julgou o homem "mais sensato, independente, justo e sábio" (Xenofonte, 1996, p.203) e, logo, o mais indicado para cumpri-la. Trata-se, pois, de estar na presença destes seres vivos que se comunicam e aprofundam o conhecimento através mesmo desta presença na qual ambos se encontram.

Sua palavra, portanto, só ganha um lugar pleno quando colocada frente ao outro que o escuta, $e$ que, ao ser afetado por ela, responde já deste novo lugar onde foi afetado, dando continuidade à interlocução pretendida por Sócrates. Está aí insta- lada a razão dialógica que impregna o método socrático e tão bem o caracteriza.

\section{O procedimento de Sócrates}

Quase poderíamos dizer que o procedimento socrático deriva logicamente destas configurações mesmas que tomam o "ensino" de Sócrates (valorizando a presença e desprezando a escrita), se não pudéssemos também supor que elas por sua vez é que são condicionadas por um procedimento cuja essência está na articulação do diálogo sobre um determinado ponto enigmático.

É justamente sobre este ponto que serve de pivô para que em torno dele se dê o diálogo - digamos, o ponto causa do diálogo-, que podemos fazer uma aproximação com o procedimento psicanalítico. Como dissemos, o diálogo socrático não é o diálogo analítico Mannoni (conforme citado por Lacan, 1978), no entanto, trata-se de poder usá-lo para pôr em evidência exatamente uma dimensão das mais importantes da operação analítica - esta dimensão de um ato que se dá em presença do outro - e, que por suas características mesmas, muitas vezes evade a conceituação que dela se faz.

Podemos, neste ponto, fazer ressaltar duas características importantes das intervenções de Sócrates, para o nosso objetivo que é aproximá-las do que se passa na análise. Em primeiro lugar, podemos dizer, que as perguntas de Sócrates velam pelo encadeamento lógico do argumento que está sendo desenvolvido. Vão como que contornando, circunscrevendo o raciocínio do interlocutor para que ele se defronte realmente com a verdade do que está sendo dito. Cuida para que não se mantenha apenas na sustentação de um dito pela pura aparência e confiança que demonstra o orador no exercício de sua fala. É, como veremos, o Sócrates que traz a grande novidade de estabelecer a episteme, que hoje, já introduzindo alterações, traduzimos por ciência. Este termo, é claro, não tinha as mesmas ressonâncias que tem atualmente para nós, mas, com os recursos que a lingüística nos fornece hoje em dia, permite que identifiquemos em Sócrates a busca de uma articulação significante consistente (Lacan, 1991/1992). Tratava-se, para ele, de "interrogar o significante sobre sua coerência de significante" (p.121). Essa é a ma- 


\section{Anna Carolina Lo Bianco}

neira como Lacan se refere ao problema fundamental que Sócrates se dedicava a investigar. Desde o Protágoras e mais especialmente no Ménon, diálogos escritos por Platão (1956; 1956a), toma uma questão que é a de tentar saber com "exatidão" qual é a essência da virtude (areté). Procura circunscrevêla em seu todo, em si mesma, perseguindo cada tentativa que Ménon faz de caracterizá-la. Esse inicia por considerar o que a virtude representa para um homem (a capacidade de lidar com os negócios da cidade), para uma mulher (a capacidade de lidar com a organização da casa, sua obediência ao marido), para uma criança, para um escravo e assim por diante (Platão, 1956a, p.116). Sócrates argumenta que o que lhe está sendo apresentado são "muitas virtudes" quando o que ele procura é o que todas "têm em comum" (Platão, s.d., p.24), é a "virtude em sua totalidade" (Jaeger, 1936/1995, p.703). O afinco com que busca uma "definição geral", nas palavras de Ménon (Platão, s.d., p.16), indubitavelmente, é o que permite a Lacan afirmar que ele busca a coerência do significante como tal.

Sócrates opõe à unicidade da virtude a multiplicidade de suas partes, e, ainda que, nesse momento, não possamos identificar uma distinção entre o "lógico universal" e o "ontológico real" (Jaeger, 1936/1995, p.705), ainda que não possamos aí reconhecer o conceito lógico tal como o entendemos atualmente, esse está, pelo menos em potencial, incluído no procedimento socrático. Tal procedimento já observa o que mais tarde viríamos a considerar a relação do conceito com a teoria na qual é articulado e da qual retira seu rigor e sua precisão. Por isso podemos seguir a leitura lacaniana e distinguir, então, o respeito às regras que delimitam o funcionamento do que chamamos uma cadeia significante. Nela os termos só ganham sua significação por relação ao lugar que ocupam, o qual vai, ao mesmo tempo, atribuir-lhes seu valor. Inaugura-se, pois, um saber que se dá por referência ao próprio jogo no qual é constituída a cadeia significante (Lacan, 1991/ 1992). Por isso, também, podemos afirmar que Sócrates é quem primeiro expressa e defende o poder da episteme (Zaloszyc,1990).

A par dessa característica que revela a episteme, levanta-se uma outra questão quando Sócrates sustenta a "tensão dialética" (Jaeger, 1936/
1995, p.632). Lacan (1992) mostra como Sócrates, porque acreditava na força da episteme, sabia como manejá-la; ao mesmo tempo sabia dos seus usos, de seus limites e, acima de tudo, de seus engendramentos. Neste sentido, é que podia recorrer a ela para apontar nos discursos anteriores ao seu, uma posição que era mantida sem que fosse acompanhada de uma reflexão que implicasse aquele que apresentava suas idéias.

Koyré (1937) dá o exemplo de Teeteto (não mais um diálogo inicial como os que nos auxiliaram até aqui). Um jovem que recebe as opiniões de Protágoras e "por amizade adota sua epistemologia" (p.61). Sócrates o interroga, apenas para constatar que este está impregnado por opiniões que atravancam sua "alma" e o impedem de perceber a verdade que já possuía. Isto é, o impedem de se implicar na busca de uma opinião verdadeira, fruto de sua própria reflexão, que o levaria a "conhecer-se a si mesmo". O conhecer-se a si mesmo de Sócrates não é, como vimos, algo que vem de fora, que é dado por alguém. Ele se refere antes à capacidade de reflexão, e, nesse sentido, não diz respeito a um desvelamento ou a um desvendar de algo "interior", mas à própria operação de construção do que vem a ser para o sujeito mesmo esse conhecimento de si.

Sócrates mostra no Ménon, como conhecer é trazer à tona reminiscências de algo que sempre se soube. Ménon procura sempre se referir ao saber de seus mestres como aquele que realmente responderia às questões de Sócrates, visto que ele, justamente por sua falta de reflexão própria, não é capaz. Sócrates lhe mostra que, ao contrário, não é preciso de um destes mestres para que seja possível encontrar as respostas procuradas. Sócrates chama um escravo para mostrar como este de fato conseguia resolver uma questão de geometria com seu parco conhecimento. Quer mostrar que este conhecimento que se articula sob a égide do significante é passível de ser manejado, até mesmo por um escravo.

No entanto, como mencionamos, Lacan (1978) afirma que Sócrates também sabia dos limites do recurso ao significante, e vem, neste momento, trazer uma contribuição muito importante exatamente sobre o que pode ser engendrado por tais limites. Usando ainda o diálogo do Ménon, nos leva a acompanhar a interrogação que Sócrates faz ao es- 
cravo, para mostrar que num dado momento há um corte de planos: de início o escravo consegue acompanhar e responder, em seguida há um ponto em que ele pára e é Sócrates quem vai lhe apresentar uma questão que possibilita a resolução do problema. Como afirma Jaeger (1936/1995) "sem o auxílio de Sócrates o escravo jamais teria dado os passos que o guiaram à descoberta daquela complicada realidade matemática" (p.709).

O que o Ménon deixa ver em relação ao ato socrático ${ }^{4}$ é como, para além do saber constituído e formal que desembocará na ciência dos dias atuais e que cristalizará e sedimentará a experiência pouco a pouco vivida, trata-se agora de reconhecer a operação que deu início a esse saber, que o tornou possível e que não se resume a ele.

É interessante, ainda nesse mesmo ponto, retomarmos o diálogo que Sócrates vinha mantendo com Ménon quando esse o acusa de feiticeiro por estar agindo como a raia que paralisa aquele que a toca. Sócrates recusa veementemente o símile dizendo que a imagem só lhe caberia se a raia também ficasse paralisada: não é que sabendo as respostas, por sua parte, fizesse os outros ficarem perplexos. Ao contrário, está, ele próprio procurando fazer nascerem tais respostas, as quais também não lhe são conhecidas. Localizamos nessa passagem o ponto nodal de "não-saber absoluto" (Zaloszic, 1990, p.14) a partir do qual vão se dar as condições de possibilidade do aparecimento de um saber significante.

Tanto em relação ao escravo, quanto à Ménon, surpreendemos a operação socrática de dirigi-los a esse ponto de não-saber, que - é importante que o frisemos ainda uma vez - é compartilhado por Sócrates. A partir daí eles se apropriarão da questão e com seus próprios recursos, auxiliados pelo procedimento de Sócrates, iniciarão o caminho que os levará na busca da verdade que é, ao mesmo tempo, obra e conclusão do diálogo.

Voltamos, então, à questão da presença de Sócrates, da força do confronto que gera um movimento atual e marcante de envolvimento, de implicação dos jovens com que fala. Através de perguntas certeiras às quais parece quase sempre impossí-

\footnotetext{
4 Na mesma linha que desenvolvendo aqui, Rudge (1988) faz uma profícua aproximação entre o que estamos chamando da "operação socrática"como o "ato analítico" teorizado por Lacan (1967-68).
}

vel evadir, procura desfazer as certezas mantidas anteriormente por seus interlocutores. É curioso examinar como nas próprias formas de elaboração das perguntas - a exortação e a indagação -, põe à prova todo o saber organizado e ensinado até então, argüindo um saber aparente que vai então desmontando através do diálogo. É importante ressaltar que apesar da declaração do oráculo de que não havia ninguém mais sábio do que Sócrates, não se deve supor que ele se considerasse, como diz Cornford (1989), "um profeta do deus de Delfos" (p.202). Segundo esse mesmo autor, "entre os homens sábios de todos os tempos, ele é talvez único no seu firme repúdio da idéia de que tinha qualquer revelação a fazer" (p.202). Por isso, rejeita o comentário de Ménon, afirmando que está tão paralisado quanto o próprio discípulo frente às questões que ambos enfrentam. $\mathrm{Na}$ verdade, não sabe a resposta. $\mathrm{E}$, por não sabê-la pode chegar ao ponto em que as perguntas ecoam no interlocutor com toda a força de um enigma o qual exige do outro um trabalho de decifração. E a dedicação daquele que se põe nesta tarefa é, para Sócrates, pode-se dizer, a resposta que procura, mais do que a sua pronta elucidação. Ou seja, começa por lhes colocar um enigma, para que eles possam constatar o quão pouco sabem, desmonta os saberes constituídos que quase sempre se articulam numa malha frouxa e artificial e, então, os tem preparados para a busca da verdade em sua companhia (Conford, 1982). Como diz este próprio autor:

"quando a busca genuína começa, ele sempre trata o outro da conversa como um companheiro e aliado, não como um oponente" (p.45).

Para concluir, diríamos que o lugar em que Sócrates se situa nos aproxima, portanto, da configuração do lugar que sabemos ser o do analista. Um lugar que ultrapassando o plano do jogo verbal, possa capturar o sujeito para fazê-lo trabalhar, para fazêlo responsável pelo que vem a expressar como seu desejo. Não lhe ensinando uma doutrina, não lhe transmitindo regras de bem viver, não escondendo, nem revelando o que possa ser a verdade do sujeito, mas apenas indicando, através de sua presença, o enigma, que, por sua vez, aponta o caminho que ele 
próprio irá construir. É neste lugar, pois, que encontramos o valor da indicação, da pontuação que só se faz efetiva e que só exerce todo seu impacto no confronto, na presença frente ao analisando, esta mesma presença que, na verdade, Freud (1912/1996) enfatizou desde sempre e que resumiu na afirmação de que não se pode analisar in absentia ou in effigie.

\section{Referências Bibliográficas}

Banfi, A.(1984). Socrate. Milano

Brun, J.(1992). Socrate. Paris: Presses Universitaires de France.

Cornford, F.M. (1982), Before and after Socrates, Cambridge University Press.

Cornford, F.M. (1989). Principium Sapientiae. As origens do pensamento filosófico grego. Lisboa: Fundação Calouste Gulbenkian

Freud, S. (1996). Sobre la dinámica de la transferencia. Em Sigmund Freud Obras Completas (J. Etcheverry,Trad.), vol.XII, (pp.93-105). Buenos Aires: Amorrortu Editores (Trabalho original de 1912).

Jaeger, W. (1995). Paidéia - A Formação do Homem Grego. (A.M. Parreira,Trad.). S.Paulo: Martins Fontes (Trabalho original de 1936)

Koyré, A. (1937). Introduction à la lecture de Platon. Paris:Gallimard.

Lacan, J. (1966). Subversion du sujet et dialectique du désir dans l'inconscient freudien. Em J. Lacan (Org.), Ecrits. Paris: Editions du Seuil

Lacan, J. (1967-68). Le Séminaire, Livre XV, L'acte psychanalytic. Inédito.

Lacan, J. (1978). Le Séminaire, Livre II, Le moi dans la théorie de Freud et dans la technique de la psychanalyse, Paris: Editions du Seuil

Lacan, J. (1992). O Seminário, Livro 8, A Transferência, (D.D.Estrada, Trad.) Rio: Jorge Zahar Editor (Trabalho original publicado em 1991)

Lasa, G.G. (1991). El expediente de Sócrates. Santiago de Chile: Editorial Universitaria
Magalhães-Vilhena, V. de (1984). O problema de Sócrates. Lisboa: Fundação Calouste Gulbenkian

Pessanha, J.A.M. (1996). Vida e Obra. Em Sócrates (Os pensadores) São Paulo: Nova Cultural.

Platão (1956). Protagoras (W.K.C. Guthrie,Trad.) Harmondsworth: Penguin Classics

Platão (1956a), Meno. (W.K.C. Guthrie,Trad.) Harmondsworth: Penguin Classics

Platão (s.d.). Ménon (A. Lobo Vilela, Trad.) Lisboa: Inquérito

Rudge, A.M. (1998). Pulsão e Linguagem - Esboço de uma concepção psicanalítica do ato. Rio: J.Zahar

Xenofontes (1996). Ditos e feitos memoráveis de Sócrates.(L.R. de Andrade, Trad.) Sócrates (Os pensadores) São Paulo: Nova Cultural.

Zaloszyc,A. (1990). 'L'atopie de Socrate. Em Socrate - perspective philosophique - perspective psychanalytiques. Strasbourg: Presses Universitaires de Strasbourg. 